\title{
Effects of pre-storage dipping in calcium chloride and salicylic acid on the quality attributes of stored Khalal Barhi dates
}

\author{
Ahmed Atia ${ }^{1,2^{*}}$, Diaeldin Abdelkarim ${ }^{1}$, Mahmoud Younis ${ }^{1}$, Abdullah Alhamdan ${ }^{1,2}$ \\ (1. Chair of Dates Industry \& Technology, College of Food \& Agricultural Sciences, King Saud University, Riyadh 11451, Saudi Arabia; \\ 2. Department of Agricultural Engineering, College of Food \& Agricultural Sciences, King Saud University, Riyadh 11451, Saudi Arabia)
}

\begin{abstract}
Barhi is a high-quality date cultivar, typically harvested and consumed fresh at the Khalal maturity stage when the fruits are crispy and sweet with bright yellow color. The shelf-life of the Khalal stage (2-3 weeks) is very short for effective marketing. This study aimed at investigating the role of calcium chloride $\left(\mathrm{CaCl}_{2}\right)$ and salicylic acid (SA) as pre-storage treatments in preserving the color and texture of the fruit during both cold and controlled atmosphere (CA) storage systems. Fresh-harvested Barhi fruits at the Khalal stage were treated with $\mathrm{CaCl}_{2}(2 \%)$ or SA $(2.0 \mathrm{mM})$, and then stored in cold and CA systems. The weight loss and decay percentages in the treated samples decreased, whereas the total soluble solids of the treated samples increased compared with those of the untreated ones. The best treatment in limiting changes in the color and texture of the fruits was $\mathrm{CaCl}_{2}$ treatment during CA storage.
\end{abstract}

Keywords: Barhi dates, calcium chloride, salicylic acid, color texture, controlled atmosphere storage DOI: $10.25165 /$ j.ijabe.20201303.4983

Citation: Atia A, Abdelkarim D, Younis M, Alhamdan A. Effects of pre-storage dipping in calcium chloride and salicylic acid on the quality attributes of stored Khalal Barhi dates. Int J Agric \& Biol Eng, 2020; 13(3): 206-212.

\section{Introduction}

Date palm (Phoenix dactylifera $\mathrm{L}$.) is an ancient fruit tree that yields berry fruits (dates), which constitute a primary food staple in the Middle East and North Africa region, where hundreds of date cultivars are grown and play a significant role in the economy, history, and culture of the people ${ }^{[1]}$. Dates are non-climacteric fruit, with shallow metabolic activity. They are considered nutritious and provide quick energy intake because of their high inverted sugar content along with minerals, vitamins, phenols, flavonoids, anthocyanin, carotenoids, and fiber with low-fat content $^{[2-6]}$. The development of date fruit goes through five maturity/ripening stages: Hababouk, Kimri, Khalal (Bisr), Rutab, and Tamer. Usually, dates are harvested and marketed at the last three stages of maturity and can be consumed soft, semi-dry or dry, depending on the cultivar features, climatic conditions, and market demand $^{[7]}$. High quality date cultivars such as Barhi are attracting a rising demand in international markets. The Barhi cultivar is a popular cultivar widely grown in the Middle East. Barhi dates are usually harvested and consumed fresh at the Khalal stage of maturity when the fruits are crispy and sweet with a bright yellow

\section{Received date: 2019-02-17 Accepted date: 2020-03-26}

Biographies: Diaeldin Abdelkarim, (PhD.), research interests: food storage, modified atmosphere storage, physical properties of foods, rheological properties, shelf life of foods, Email: delkhair@ksu.edu.sa; diaeldin@gmail.com; Mahmoud Younis, (PhD.), research interests: modified atmosphere storage, physical properties of foods, rheological properties, shelf life of foods, Email: younis_b2011@yahoo.com; Abdullah Alhamdan, (Prof.), research interests: postharvest technology and date processing, food storage, modified atmosphere storage, physical properties of foods, rheological properties, shelf life of foods, Email: Alhamdan@ksu.edu.sa.

*Corresponding author: Ahmed Atia, (Msc.), research interest: food preservation, control atmosphere storage, NIR spectroscopy, Address: CDIT and Dept. of Agricultural Engineering, College of Food \& Agricultural Sciences; King Saud University; Riyadh 11451; Saudi Arabia. Email: 435108667@ student.ksu.edu.sa. skin color. After harvesting, Barhi dates rapidly converts to the Rutab stage (in few days) where their tissues become softer, and their skin color turns to brown; at this stage, however, their consumer demand and market price decrease significantly ${ }^{[7]}$. Therefore, slowing fruit ripening after harvesting to extend their shelf life is crucial for marketing the harvested Barhi dates.

Postharvest storage life of fruits and vegetables can be extended by cold storage as well as controlled atmosphere (CA) storage. Furthermore, postharvest treatments, such as dipping in aqueous $\mathrm{CaCl}_{2}$ or $\mathrm{SA}$, could be used to improve the storability of several types of horticultural produce ${ }^{[8-10]}$. Dipping in $\mathrm{CaCl}_{2}$ has been used for regulating fruit ripening, retaining fruit color and texture, and extending the postharvest life for figs, blackberries, raspberries, and strawberries ${ }^{[9,11]}$. Similarly, salicylic acid (SA) a natural and safe phenolic plant compound, is used mainly in regulating postharvest losses of horticultural produce ${ }^{[12]}$. Several studies have addressed the effects of SA on bananas, kiwifruit, navel oranges, and plums ${ }^{[13-16]}$.

It appears that data on the effects of postharvest treatments on the storability of fresh Barhi dates has been limited. The objective of this current work was to investigate the influence of postharvest dipping in aqueous $\mathrm{CaCl}_{2}$ and $\mathrm{SA}$ on the weight loss, fruit decay, total soluble solids (TSS), color, and texture of Barhi dates at the Khalal stage during cold and CA storage.

\section{Materials and methods}

\subsection{Materials}

Fresh Khalal Barhi dates were obtained from a commercial farm in Riyadh, Saudi Arabia and transferred on the same day to King Saud University (CDIT/Food Processing Laboratories). The dates were sorted for uniformity in maturity and color and cleaned to remove dust and adherent dirt. The data on the initial physical properties (mass, volume, length, diameter, moisture content, TSS\%, and color values ( $L, a$, and $b)$ of the dates were measured and presented in Table 1 . 
Table 1 Basic physical properties of fresh Barhi fruits at Khalal stage of maturity

\begin{tabular}{|c|c|c|c|c|c|c|c|c|c|}
\hline \multirow{2}{*}{ Property } & \multirow{2}{*}{ Mass/g } & \multirow{2}{*}{$\begin{array}{l}\text { Volume } \\
/ \mathrm{cm}^{3}\end{array}$} & \multirow{2}{*}{$\begin{array}{l}\text { Length } \\
/ \mathrm{mm}\end{array}$} & \multirow{2}{*}{$\begin{array}{l}\text { Diameter } \\
/ \mathrm{mm}\end{array}$} & \multirow{2}{*}{$\begin{array}{l}\text { Moisture content } \\
\text { (w.b) } / \%\end{array}$} & \multirow{2}{*}{$\mathrm{TSS} / \%$} & \multicolumn{3}{|c|}{ Color values } \\
\hline & & & & & & & $L$ & $a$ & $b$ \\
\hline Mean & $9.23 \pm 0.42$ & $10.08 \pm 0.65$ & $28.70 \pm 0.14$ & $23.19 \pm 0.25$ & $66.28 \pm 1.02$ & $26.31 \pm 0.27$ & $52.48 \pm 0.91$ & $2.04 \pm 0.40$ & $30.40 \pm 0.54$ \\
\hline $\mathrm{n}$ & 50 & 50 & 50 & 50 & 50 & 50 & 50 & 50 & 50 \\
\hline
\end{tabular}

\subsection{Treatments}

Barhi dates were randomly divided into three collections for the following treatments in triplicate: the first set was immersed for 5 min in an aqueous solution of $\mathrm{CaCl}_{2}(2 \%)$, the second in SA $(2 \mathrm{mM})$, and the third set was immersed in distilled water (control). Concentrations of $\left(\mathrm{CaCl}_{2}\right)$ and (SA) were chosen from preliminary experiments. Dipping of the samples was done using perforated plastic containers (approximately $10 \mathrm{~kg}$ each). Subsequently, the samples were left to dry at room temperature $\left(25^{\circ} \mathrm{C}\right)$ then placed into cold storage $\left(0^{\circ} \mathrm{C}, 80 \% \pm 5 \% \mathrm{RH}\right)$ and CA storage $\left(0^{\circ} \mathrm{C}, 5 \% \mathrm{O}_{2}\right.$, $\left.5 \% \mathrm{CO}_{2}, 80 \% \pm 5 \% \mathrm{RH}\right)$.

\subsection{Measurements}

The various quality characteristics of the Barhi dates were taken at the beginning for the fresh samples and then measured at $10 \mathrm{~d}$ intervals during cold storage and $20 \mathrm{~d}$ intervals during CA storage. The experiments were performed when the stored samples reach room temperature $\left(25^{\circ} \mathrm{C}\right)$. The tests were terminated after $40 \mathrm{~d}$ and $120 \mathrm{~d}$ for cold storage and CA storage, respectively, when the samples became $50 \%$ Rutab or decayed.

The weight of the samples was determined by a digital balance (Model 204, Mettler, Toledo, Switzerland). The fruit weight loss was calculated based on the initial weight and expressed in percent. The total soluble solids (TSS)\% of the samples was measured at room temperature $\left(25^{\circ} \mathrm{C}\right)$ using a digital refractometer (Abbe 5 Refractometer, Bellingham \& Stanley (BS), Jena, Germany) and expressed as a percentage ${ }^{[17]}$. Samples were frequently checked for decay (Rutab or deteriorated) during the testing. The percent decay was calculated according to:

$$
\text { Fruit decay }(\%)=\left[\frac{\text { Number of decayed fruits }}{\text { Total number of fruits }}\right] \times 100
$$

A Hunter Lab-scan XE spectrophotometer was used to measure Hunter basic color parameters $(L, a$, and $b)$ for the samples, where parameter $(L)$ indicates brightness/darkness, parameter $(a)$ indicates redness/greenness, and parameter $(b)$ indicates yellowness/blueness. The average values of the basic color parameters $\left(L^{*}, a^{*}\right.$, and $\left.b^{*}\right)$ were used to calculate the derivative color parameters (total color difference $(\Delta E)$, Chroma, and hue angle $(\mathrm{H}))$ as defined by Maskan ${ }^{[18]}$.

A texture analyzer (TA-HDi, Model HD3128, Stable Micro Systems, Surrey, England) was used to measure the textural profile analysis (TPA) parameters of the Barhi dates. The samples were compressed to a depth of $5 \mathrm{~mm}$ with a cylinder at a velocity of $1.5 \mathrm{~mm} / \mathrm{s}$. The resultant force-time deformation of two curves were used in determining the hardness, elasticity, and chewiness of the Barhi dates ${ }^{[19]}$.

\subsection{Sensorial attributes}

The sensory evaluation of the quality of the fresh and stored Barhi dates was conducted using the 9-point hedonic scale ${ }^{[20]}$. The evaluated sensory qualities were: texture, taste, color, and overall acceptability. The responses were converted to numbers ranging from 1 for "dislike extremely" to 9 for "like extremely" with 5 for "neither like nor dislike".

\subsection{Data analysis}

The obtained data were examined by the analysis of variance
(ANOVA) test using SPSS software package (IBM SPSS version 22). The statistical differences between the calculated means were established by the least significant difference (LSD) multi-comparison test and significant differences were reported at $p$-value $\leq 0.05$.

\section{Results and discussion}

\subsection{Fruit weight loss}

Barhi dates exhibit a considerable loss of weight through the first $20 \mathrm{~d}$ of storage; however, afterward the weight decreased at a lower rate Figure 1a. Nevertheless, in CA storage, the change in weight was lower with minor changes at some storage periods. It can be observed that for both cold and CA storage, the weight loss in the control samples was significantly higher than that of the treated samples. The lowest weight loss was observed for $\mathrm{CaCl}_{2}$-dipped samples during the $\mathrm{CA}$ storage followed by the SA-dipped samples. After $40 \mathrm{~d}$ in cold storage, the control showed a $3.37 \%$ loss in weight, yet the percentages of weight loss of treated samples were $3.15 \%$ and $2.70 \%$ for $\mathrm{SA}$ and $\mathrm{CaCl}_{2}$, respectively. Meanwhile, at the end of CA storage (120 d), the control showed a $2.14 \%$ loss in weight, and the percentage of weight loss of the treated samples were $1.33 \%$ and $2.01 \%$ for $\mathrm{CaCl}_{2}$ and SA, respectively.

During the first $20 \mathrm{~d}$, no significant differences were seen between the two dipping treatments for either cold storage or CA storage. However, the weight loss of the $\mathrm{CaCl}_{2}$-treated samples in CA storage was significantly lower than that of the control samples in cold storage. On the $40^{\text {th }}$ day in cold storage, significant differences were observed between the control and the SA-treated samples. Significant differences were found between the $\mathrm{CaCl}_{2}$-treated samples and the other samples during the CA storage method after $60 \mathrm{~d}, 80 \mathrm{~d}, 100 \mathrm{~d}$, and $120 \mathrm{~d}$.

Generally, the loss in fruit weight is caused by the deficiency of moisture due to transpiration, respiration and vapor pressure deficit (VPD) among the adjacent air and the fruits. The loss in moisture causes a rapid rise in the concentration of sugars, leading to the maturation of the fruit ${ }^{[21]}$. Dipping in $\mathrm{CaCl}_{2}$ and $\mathrm{SA}$ restrain the removal of moisture through the fruit skin and postpone the respiration rate by constraining ethylene biosynthesis and hence reducing fruit weight loss ${ }^{[13,22]}$. Dipping in $\mathrm{CaCl}_{2}$ proved to be more effective in reducing weight loss as compared with dipping in $\mathrm{SA}$ or water (control). The effectiveness of $\mathrm{CaCl}_{2}$ treatment in decreasing weight loss is due to the increase in moisture holding capacity and reduction in moisture evaporation ${ }^{[23]}$. The obtained results for the weight loss are similar to those stated in previous studies for blackberry, raspberry and strawberry, apple, and peach fruits $^{[11,24,25]}$.

\subsection{Total soluble solids (TSS)}

The TSS of the treated and control samples of Barhi dates increased with storage time during both storage methods Figure $2 b$. The smallest variations in TSS were apparent for the $\mathrm{CaCl}_{2}$-dipped samples during CA storage. This might be due to the influence of calcium in reducing the ethylene production, respiration rate, and enzyme activity, thus, delaying fruit maturation and changes in color. 


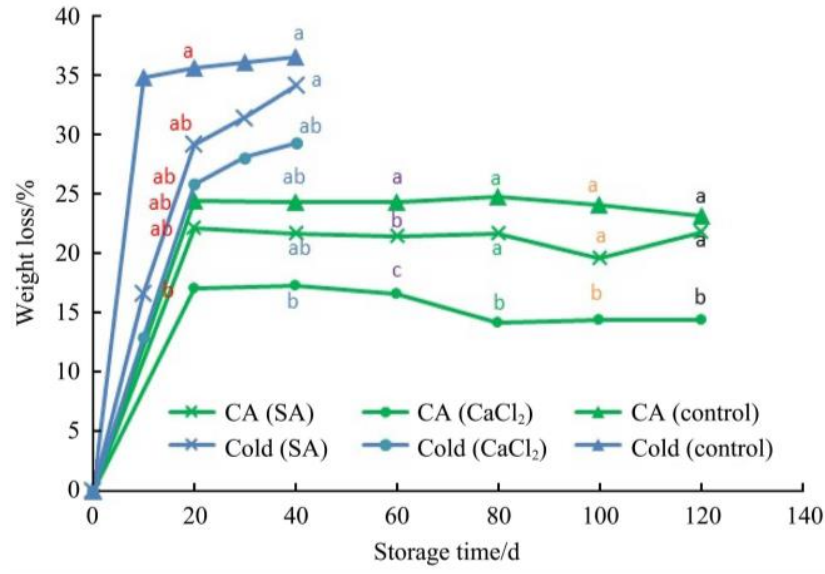

a.

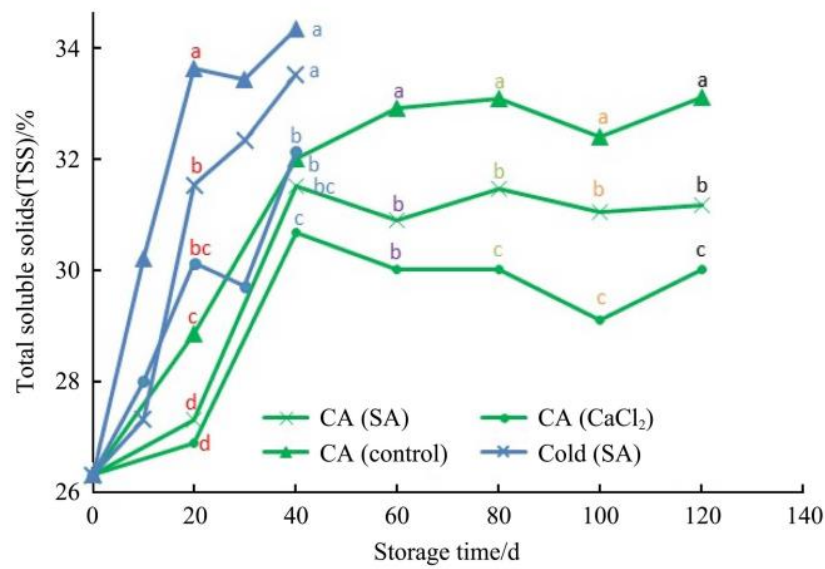

b.

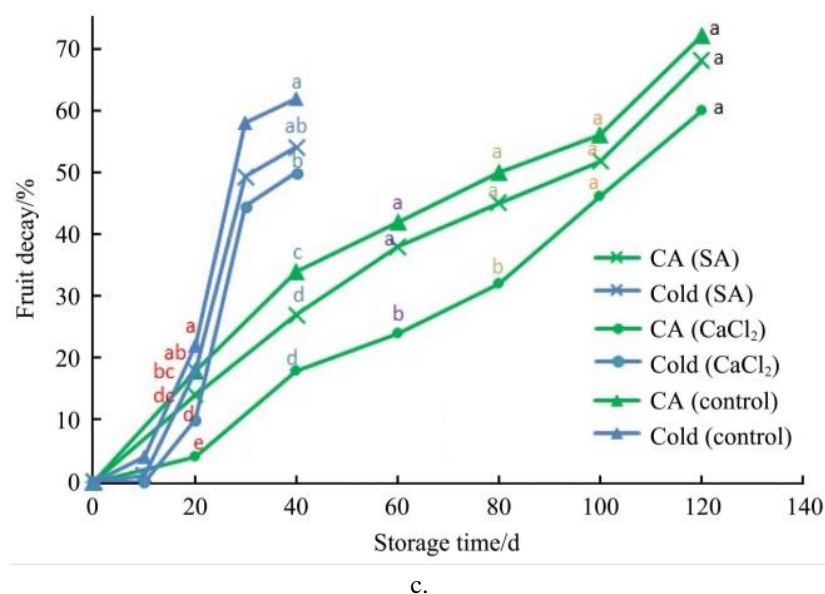

Note: Means with different letters in treatment indicate significant differences between the groups in the vertical direction according to LSD test $(p \leq 0.05)$ $(n=5)$.

Figure 1 Changes in weight loss, TSS\%, and fruit decay\% in Barhi fruits as affected by pre-storage dipping in $\mathrm{CaCl}_{2}$ and $\mathrm{SA}$ and by the time during cold and CA storage methods

At the end of the cold storage ( $40^{\text {th }}$ day), TSS of the control sample increased by $30.5 \%$, whereas, after $120 \mathrm{~d}$ in the CA storage the increase in TSS of the control sample was $25.8 \%$. On the $40^{\text {th }}$ day in the cold storage the increase in TSS of $\mathrm{CaCl}_{2}$-treated samples was $22 \%$, however, it was reduced to $14 \%$ after $60 \mathrm{~d}$ in the CA storage.

Through CA storage up to $60 \mathrm{~d}$, the changes in TSS of the treated samples were not significantly different. However, the increases in the TSS values of the treated samples in cold storage was significantly higher than those in CA storage. After $80 \mathrm{~d}$ and until the end of CA storage, the variation in the TSS\% of the
$\mathrm{CaCl}_{2}$-treated samples was significantly lower than that of the other samples.

Hussain et al. ${ }^{[24]}$ reported that the increase in the TSS of fruits in storage is due to the moisture reduction and enzyme activity in changing complex polysaccharides into simple sugars. The reduced increase in the TSS of the treated samples could be attributed to dipping in $\mathrm{CaCl}_{2}$ or $\mathrm{SA}$, which makes a thin coating on the surface of the dates that reduces moisture and weakening the changing process. Analogous results were found in similar studies on jamun (syzygiumcuminiskeels) fruits, strawberries, and apple fruits ${ }^{[26-28]}$.

\subsection{Fruit decay}

The percentage of fruit decay in treated and control samples increased with storage time during both cold and CA systems Figure 1c. The increase in fruit decay was higher during cold storage compared to CA storage for all samples.

During both storage methods, the highest fruit decay\% was attained by the control samples, whereas the lowest fruit decay\% was acquired by $\mathrm{CaCl}_{2}$-treated dates. At the $40^{\text {th }}$ day in cold storage, the fruit decay percentages of the control and the SA- and $\mathrm{CaCl}_{2}$-treated samples were $62 \%, 54 \%$, and $49 \%$, respectively. However, in CA storage, fruit decay percentages of $72 \%, 68 \%$, and $60 \%$, respectively, were observed after $120 \mathrm{~d}$. Post-harvest dipping in $\mathrm{CaCl}_{2}$ of sugar apples confirmed an affirmative influence on delaying the biochemical and physiological processes that enhance fruit maturation ${ }^{[29]}$. Zhang et al. ${ }^{[14]}$ stated that dipping in SA decreases fruit respiration and weight loss by closing tiny holes in the fruit skin, consequently, postponing maturation, senescence, and fruit decay during storage.

\subsection{Fruit color}

\subsection{1 $L, a$, and $b$ color values}

The means of the initial values of $L, a$, and $b$ of the fresh Barhi dates were 52.48, 2.04, and 30.04, respectively; these high values indicate that fresh Barhi dates exhibited bright yellow skin color. The effects of $\mathrm{CaCl}_{2}$ and SA dipping on the values of $L, a$, and $b$ of the Barhi dates during cold and $\mathrm{CA}$ storage are presented in Figure 2.

Figures $2 \mathrm{a}$ and $2 \mathrm{c}$ show that the $L$ and $b$ values decreased for all samples during storage, illustrating that the skin color of the samples was becoming less bright and browner. The two figures indicate that $\mathrm{L}$ and $\mathrm{b}$ values decreased at a faster rate during the first $20 \mathrm{~d}$ in both CA and cold storage. Moreover, the $L$ and $b$ values for the SA-treated and the control samples in cold storage decreased significantly compared with their values in CA storage. The largest reduction in the $L$ and $b$ values was detected for the control in cold storage, while the smallest reduction in their values was observed for the $\mathrm{CaCl}_{2}$-treated dates in $\mathrm{CA}$ storage. Figure $2 \mathrm{~b}$ shows that, for all samples, the value of $a$ rises with storage period for both storage systems. This demonstrates a more apparent redness in the color of the dates. The $\mathrm{CaCl}_{2}$-treated dates in CA storage exhibited minimal changes in the values of parameter $a$. The noticed delay in the color change of the samples treated with $\mathrm{CaCl}_{2}$ might be due to the retarding action of $\mathrm{CaCl}_{2}$ on the synthesis of ethylene and, hence, the reduction in the respiration rate of the fruits ${ }^{[9,11]}$.

\subsubsection{Derivative color parameters}

The changes in the derivative color parameters $(\Delta \mathrm{E}$, Chroma, and hue angle) of the treated and control Barhi dates during cold and CA storage are displayed in Figure 3. The total color difference $(\Delta E)$ is a colorimetric feature for describing color changes in the processed food. The Chroma parameter specifies 
the color saturation degree, and it is comparable to its intensity. The hue angle is an additional factor for describing food color ${ }^{[18]}$. As seen in Figure $3 a$, the total color difference $(\Delta E)$ increased with storage time during both storage systems for all samples. The $\Delta \mathrm{E}$ values of all cold-stored samples are higher compared to those of CA-stored ones. This indicates the effectiveness of CA storage in preserving the color of the Barhi fruits compared to cold storage. At the end of the cold storage, the values of $\Delta E$ for the control, SA-treated, and $\mathrm{CaCl}_{2}$-treated dates were 18.07, 13.74, and 10.72, respectively. In contrast, after $120 \mathrm{~d}$ in CA storage $\Delta E$ values for the control, SA-treated, and $\mathrm{CaCl}_{2}$-treated dates were $14.70,10.52$, and 7.06, respectively. There were significant differences in the $\Delta E$ values of the tested samples within each storage technique. After $40 \mathrm{~d}$ of storage, significant differences in the $\Delta E$ values were observed between the same treatments in both storage methods. The $\Delta \mathrm{E}$ values of the control in the $\mathrm{CA}$ storage were not significantly different from those of the $\mathrm{CaCl}_{2}$-treated samples in cold storage.

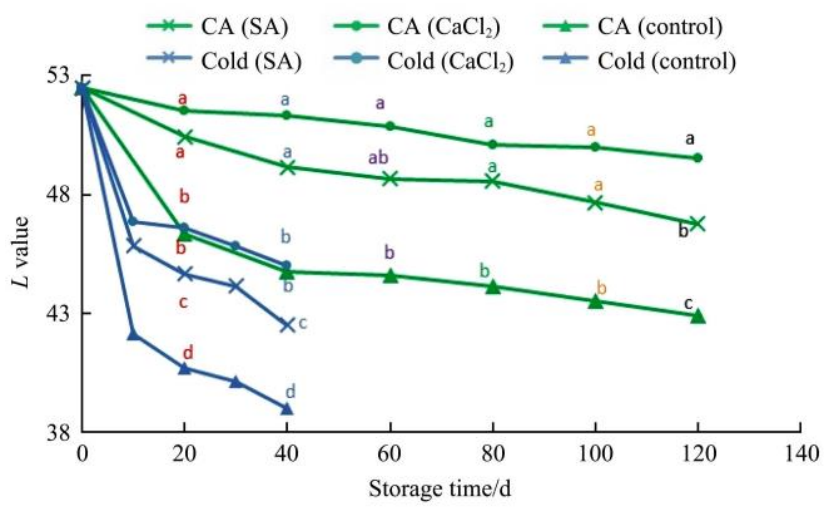

a.

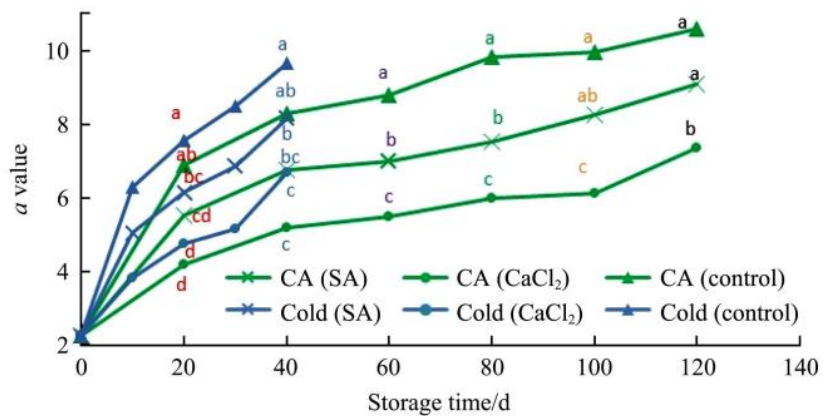

b.

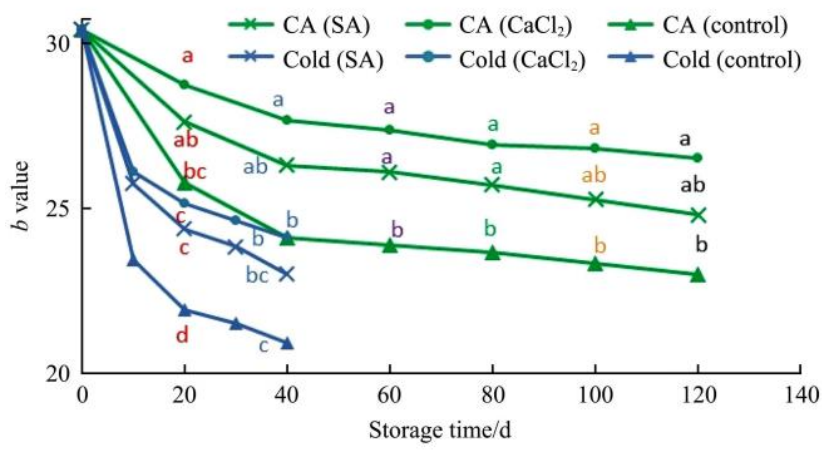

c.

Note: Means with different letters in treatment indicate significant differences between the groups in the vertical direction according to LSD test $(p \leq 0.05)$ $(n=5)$.

Figure 2 Changes in the basic colour parameters of Barhi dates as affected by dipping in $\mathrm{CaCl}_{2}$ and $\mathrm{SA}$ and by the time during cold and $\mathrm{CA}$ storage methods

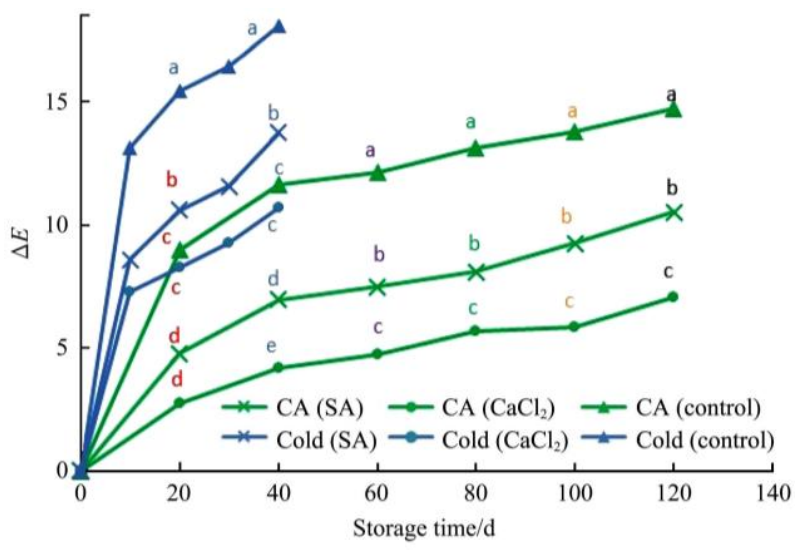

a.

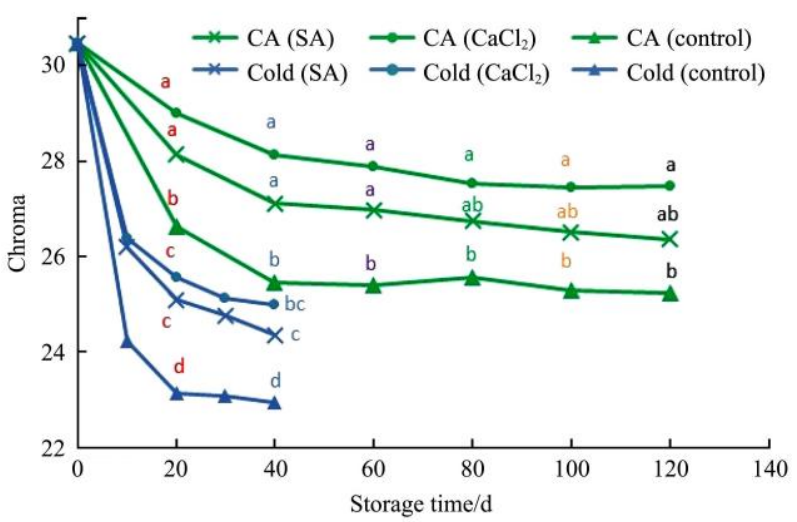

b.

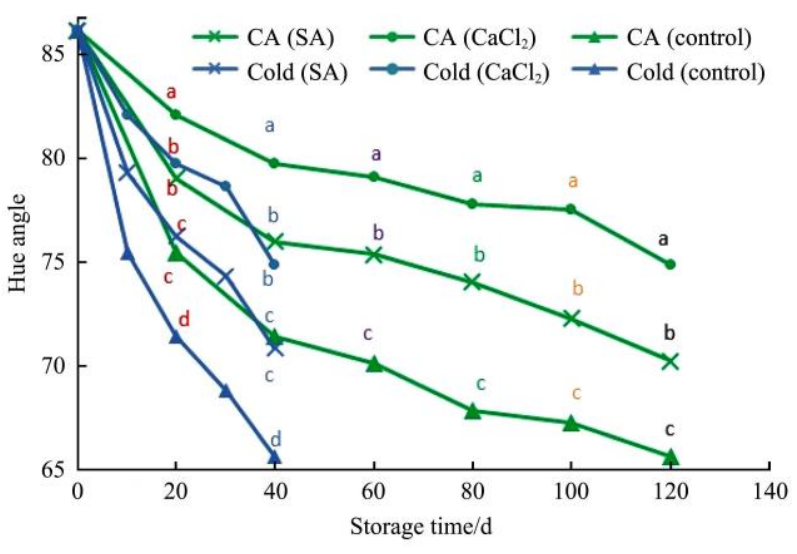

Note: Means with different letters in treatment indicate significant differences between the groups in the vertical direction according to LSD test $(p \leq 0.05)(n=5)$.

Figure 3 Changes in the derivative color parameters of Barhi dates as affected by dipping in $\mathrm{CaCl}_{2}$ and $\mathrm{SA}$ and by the time during cold and $\mathrm{CA}$ storage methods

The initial mean values of Chroma and hue angle were 30.47 and 86.13 , respectively. The values of Chroma and hue angle of all tested samples decreased with storage time for both storage techniques (Figures $3 \mathrm{~b}$ and $3 \mathrm{c}$ ). The largest decrease in Chroma and hue angle values was noticed for the control dates in cold storage, and the smallest decrease was observed for $\mathrm{CaCl}_{2}$-treated dates in CA storage. After the $40^{\text {th }}$ day up to the completion of $\mathrm{CA}$ storage, the value of hue angle for the $\mathrm{CaCl}_{2}$-treated dates were significantly higher than the hue angle of all other samples. Significant differences were noticed between the Chroma values of the treated samples in CA storage and all samples in cold storage.

These results showed that dipping in $\mathrm{CaCl}_{2}$ yielded the optimal outcome in preserving the color of Barhi dates during $\mathrm{CA}$ storage. The effectiveness of $\mathrm{CaCl}_{2}$ treatment in preserving the color of 
Barhi dates during storage can be attributed to the influence of calcium in delaying enzymatic actions, respiration rate, and ethylene production. These findings are compatible with other research studies that reported the beneficial effects of calcium post-harvest treatments in delaying the natural physiological and biochemical changes that initiate ripening and color change during low-temperature storage ${ }^{[9,26]}$

\subsection{Textural parameters}

Fruit textural properties such as hardness, elasticity, and chewiness are very important parameters that affect consumer acceptance. The impact of $\mathrm{CaCl}_{2}$ - and SA-dipping treatments on these textural properties for the Barhi dates during cold and CA systems are shown in Figure 4.

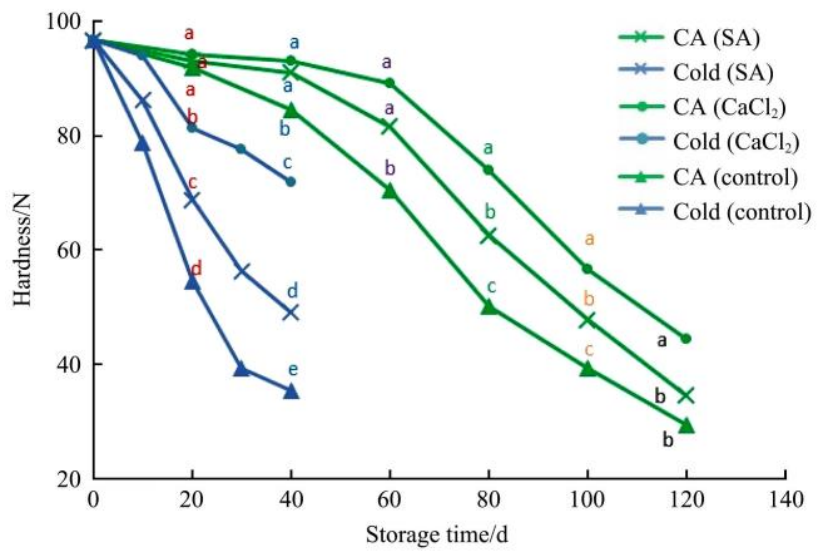

a.

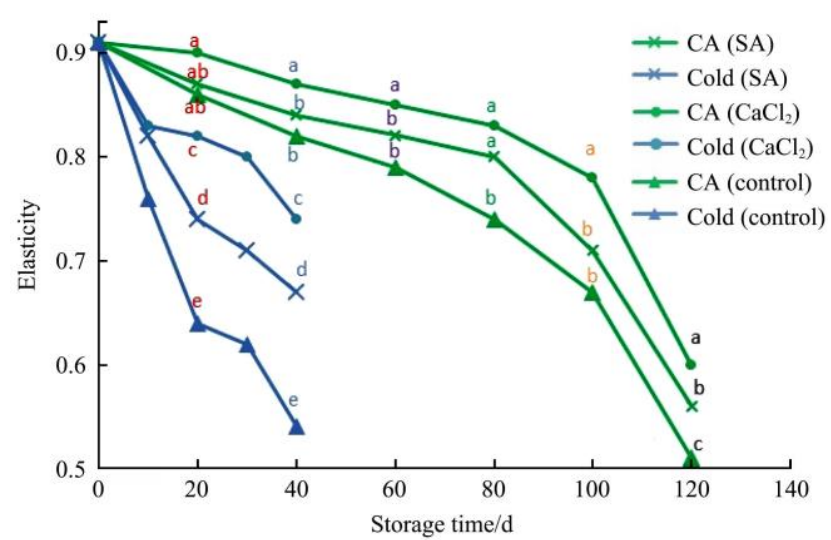

b.

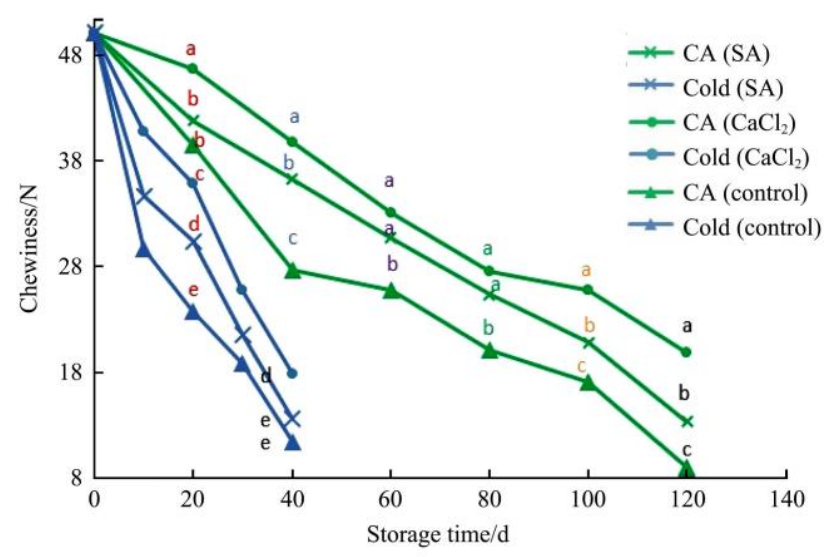

c.

Note: Means with different letters in treatment indicate significant differences between the groups in the vertical direction according to LSD test $(p \leq 0.05)(n=5)$.

Figure 4 Changes in the textural parameters of Barhi dates as affected by dipping in $\mathrm{CaCl}_{2}$ and $\mathrm{SA}$ and by the time during cold and CA storage methods
The fruit hardness initial mean value for the Barhi dates was 96.6 N. Figure $4 a$, shows that the hardness of the tested Barhi dates decreased with storage time for all treated and untreated samples. However, during cold storage, hardness was reduced at a higher rate than during CA storage. At the end of $40 \mathrm{~d}$ in cold storage, the hardness of the control decreased by $63 \%$, compared to $26 \%$ for the $\mathrm{CaCl}_{2}$-treated dates. At the end of $120 \mathrm{~d}$ in $\mathrm{CA}$ storage, the control hardness decreased by $69 \%$, while that of the $\mathrm{CaCl}_{2}$-treated dates decreased by $54 \%$. The lowest decrease in fruit hardness during storage occurred for $\mathrm{CaCl}_{2}$ treatment followed by SA treatment. Controlled atmosphere storage was significantly superior in maintaining the hardness of stored Barhi dates compared to cold storage. The hardness of the treated and control samples started to decrease significantly after $20 \mathrm{~d}$ in CA storage. Similarly, no significant differences between the $\mathrm{CaCl}_{2^{-}}$and SA-treated samples were observed after $40 \mathrm{~d}$ and $60 \mathrm{~d}$, respectively, in CA storage. However, starting from the $80^{\text {th }}$ day in CA storage, the reduction in hardness of $\mathrm{CaCl}_{2}$-treated samples was significantly lower compared to other samples.

The fruit elasticity initial mean value for the Barhi dates was 0.88 . From Figure $4 \mathrm{~b}$ it is apparent that the fruit elasticity values of Barhi dates declined with time for all tested samples during storage. The lowest loss of elasticity was achieved by the dates dipped in $\mathrm{CaCl}_{2}$ during $\mathrm{CA}$ storage. Meanwhile, the largest loss in elasticity was seen for the control during cold storage. The percentage losses of elasticity of the control, $\mathrm{SA}-$, and $\mathrm{CaCl}_{2}$-treated dates at the end of $40 \mathrm{~d}$ in cold storage were $42.0 \%, 27.3 \%$, and $19.3 \%$, respectively. However, the elasticity values of the control, SA-treated and $\mathrm{CaCl}_{2}$-treated samples at the end of $120 \mathrm{~d}$ in CA storage were reduced by $45.5 \%, 39.8 \%$, and $35.2 \%$, respectively. At the $20^{\text {th }}$ day in CA storage, the elasticity values of all stored samples were not significantly different. The elasticity values of all cold-stored samples were significantly lower compared to their equivalents in CA storage. Starting from the $40^{\text {th }}$ day up to the last day in CA storage, the values of the elasticity for the $\mathrm{CaCl}_{2}$-treated samples were significantly higher than those of other samples.

The chewiness initial mean value of the Barhi dates was $49.8 \mathrm{~N}$. Figure $4 \mathrm{c}$ clearly shows that the chewiness value of the Barhi dates decreased with storage time for all treated and untreated samples during storage. The smallest reduction in chewiness was attained by the $\mathrm{CaCl}_{2}$-treated dates, whereby the control attained the largest reduction during both storage systems. At the $40^{\text {th }}$ day in cold storage, the chewiness of the control acquired a reduction of $77.6 \%$ in chewiness, compared to a reduction of $64.9 \%$ for the $\mathrm{CaCl}_{2}$-treated dates. By the end of CA storage, the chewiness of the control had decreased by $82.6 \%$. The lowest decrease in fruit chewiness was noted in the $\mathrm{CaCl}_{2}$-treated dates during CA storage. The highest decrease was attained by the control in cold storage. CA storage was significantly superior in maintaining the stored fruit chewiness, compared to cold storage. The reduction in chewiness of the treated and control samples was not statistically different until the $20^{\text {th }}$ day in CA storage. Likewise, no significant differences were seen between the $\mathrm{CaCl}_{2}$ - and SA-treated samples after $40 \mathrm{~d}$ and $60 \mathrm{~d}$, respectively, in CA storage. Starting from the $80^{\text {th }}$ day in CA storage, the reduction in chewiness of the $\mathrm{CaCl}_{2}$-treated samples was significantly lower compared to the other samples.

The results as mentioned above show that dipping in $\mathrm{CaCl}_{2}$ followed by dipping in SA preserved the texture of Barhi dates during storage compared to the control. This consequence could be attributed to that Calcium increases the fruit hardness by making the cells firm, postpone softening and reduces fruit decay ${ }^{[30]}$ Also, 
Calcium protects the cells from enzymes that ruined the cell walls ${ }^{[31]}$. Similar results of the effect of $\mathrm{CaCl}_{2}$ on preserving fruit texture were stated by other authors ${ }^{[27,28]}$. Moreover, SA pretreatment maintenance of fruit texture has been known for some fruits and vegetables such as apple, orange, peach, banana, kiwifruit, and tomato ${ }^{[12]}$.

\subsection{Sensory quality attributes}

The sensorial outcomes for the chosen quality attributes of
Barhi dates as influenced by post-harvest dipping in $\mathrm{CaCl}_{2} / \mathrm{SA}$ and time in cold and CA storage are given in Table 2. The sensorial initial mean scores for the quality attributes of the fresh dates ranged between 8.2 and 8.9 on a scale of 1-9, designating the high quality of the fresh Barhi dates. From the data in the Table 2, it is evident that the scores for all samples decreased with storage time during both cold and CA storages. This indicates the deterioration of Barhi date quality with storage time.

Table 2 Results on sensory quality attributes of Barhi fruits as affected by treatments and storage time during cold and controlled atmosphere storage, treatment means with different letters indicate significant differences according to LSD test (p-value $\leq \mathbf{0 . 0 5}$ ) $(n=5)$

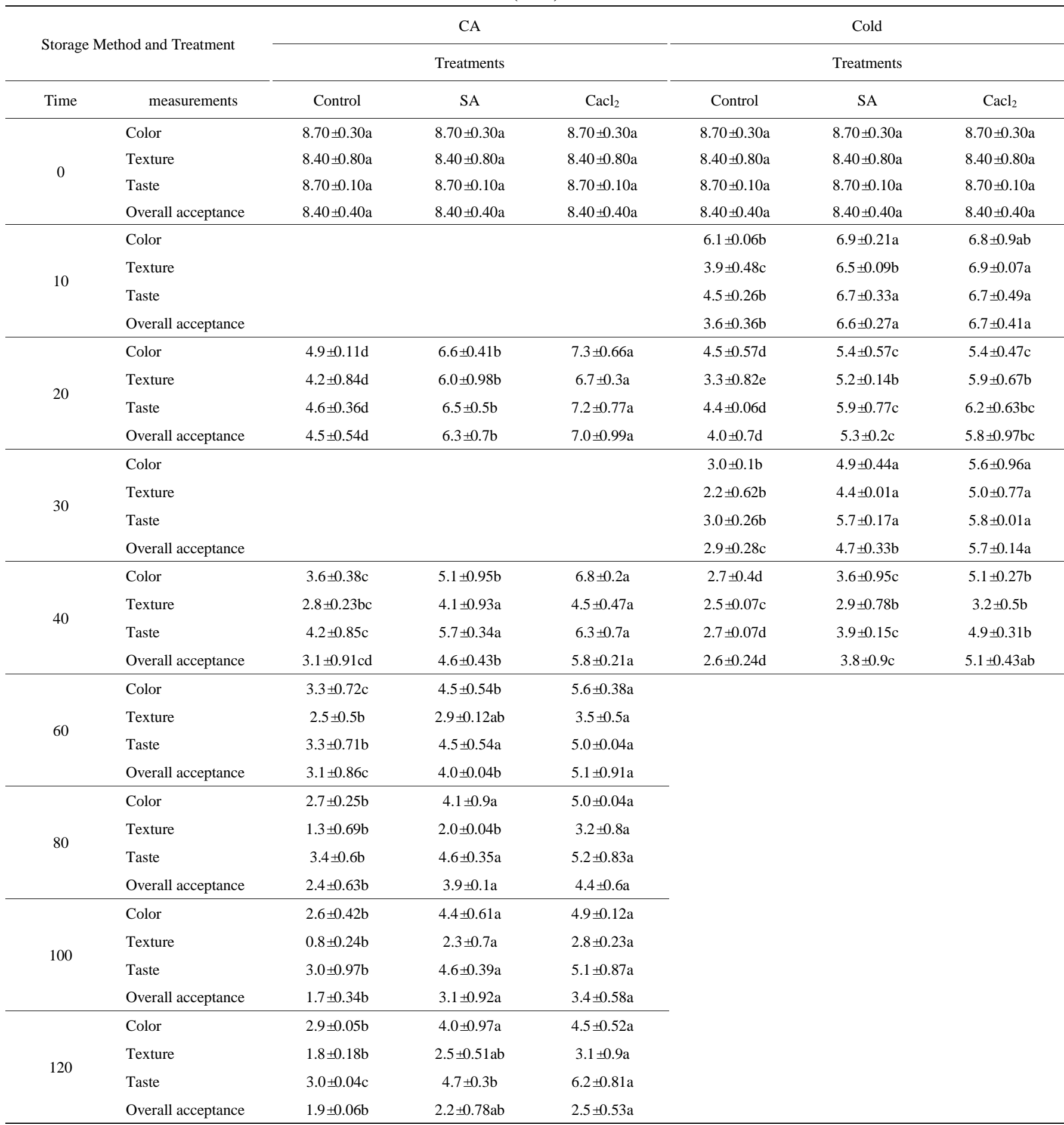

At the end of cold storage $\left(40^{\text {th }}\right.$ day), the average overall acceptance scores for the control, SA-treated, and $\mathrm{CaCl}_{2}$-treated dates were 2.6, 3.8, and 5.1, respectively, on a scale of 1-9. This demonstrates a lower quality of fruit, especially with control and
SA-treated samples. Meanwhile, at the $40^{\text {th }}$ day in CA storage, the scores were $3.1,4.6$, and 5.8, respectively. These data indicate that samples stored in CA are better in quality compared to those in cold storage. At the $120^{\text {th }}$ day in CA storage, the overall 
acceptance scores for the control, $\mathrm{CaCl}_{2}$-treated, and SA-treated dates were $1.9,2.2$, and 2.5 , respectively, indicating poor quality for all samples.

The highest sensory quality scores were achieved by $\mathrm{CaCl}_{2}$-treated dates in CA storage. This sensory evaluation is in agreement with other experimental results in that post-harvest dipping in $\mathrm{CaCl}_{2}$ with $\mathrm{CA}$ storage is effective in preserving the quality of Barhi dates at the Khalal stage of maturity and in delaying the ripening of the fruits. The lowest scores were obtained by the control at the end of the cold storage and also at the end of the CA storage. This may possibly be due to the increased enzyme activities, reduced TSS\%, and softening of the texture of Barhi dates during the long storage time ${ }^{[9,11,24,29]}$.

\section{Conclusions}

It can be concluded that dipping in $2 \%$ of $\mathrm{CaCl}_{2}$ aqueous solution or SA $(2.0 \mathrm{mmol} / \mathrm{L})$ as postharvest treatments help to preserve the quality and enhanced storability of Barhi dates at Khalal maturity stage during cold and controlled atmosphere storage. Weight loss $\%$, fruit decay $\%$, TSS $\%$ were decreased with advancing of storage time for treated samples compared to untreated samples (control) during both storage methods. Postharvest dipping in $2 \% \mathrm{CaCl}_{2}$ gave the best results in conserving the color and texture of Barhi dates during storage, especially in the CA storage. The sensorial quality of Barhi dates treated with $\mathrm{CaCl}_{2}$ was relatively satisfactory after $40 \mathrm{~d}$ in controlled atmosphere storage.

\section{Acknowledgements}

The authors are grateful to the Deanship of Scientific Research, King Saud University for funding through the Vice Deanship of Scientific Research Chairs.

\section{[References]}

[1] Yahia E M, Lobo M, Kader. A. Harvesting and Postharvest Technology of Dates. In Dates: Postharvest Science, Processing Technology and Health Benefits. Siddiq M, Aleid S M, Kader A A (eds). John Wiley \& Sons, Ltd, Chichester, UK, 2014; pp.105-135.

[2] Al-Farsi M, Alasalvar C, Morris A, Baron M, Shahidi F. Comparison of antioxidant activity, anthocyanins, carotenoids, and phenolics of three native fresh and sun-dried date (Phoenix dactylifera L.) varieties grown in Oman. J Agric. Food Chem., 2005; 53(19): 7592-7599.

[3] Boudries H, Kefalas P, Hornero-Méndez D. Carotenoid composition of Algerian date varieties (Phoenix dactylifera) at different edible maturation stages. Food Chem., 2007; 101: 1372-1377.

[4] Elleuch M, Besbes S, Roiseux O, Blecker C, Deroanne C, Drira N, et al. Date flesh: Chemical composition and characteristics of the dietary fiber. Food Chem., 2008; 111(3): 676-682.

[5] Kulkarni S G, Vijayanand P, Aksha M, Reena P, Ramana K V R. Effect of dehydration on the quality and storage stability of immature dates (Pheonixdactylifera). LWT-Food Science and Technology, 2008; 41: 278-283.

[6] Biglari F, AlKarkhi A F M, Easa M A. Cluster analysis of antioxidant compounds in dates (Phoenix dactylifera): Effect of long-term cold storage. Food Chem., 2009; 112: 998-1001.

[7] Al-Qurashi A D, Awad M A. Quality characteristics of bisir 'Barhee' dates during cold storage as affected by postharvest dipping in gibberellic acid, naphthalene acetic acid and benzyladenine. Fruits 2011; 66: 343-352.

[8] Gharezi M, Joshi N, Sadeghian E. Effect of postharvest treatment on stored cherry tomatoes. J. Nutr. Food Sci. 2012; 2(8): 1-10.
[9] Irfan P K, Vanjakshic V, Prakash M N K, Ravi R, Kudachikar V B Calcium chloride extends the keeping quality of fig fruit (Ficuscarica $\mathrm{L}$.) during storage and shelf-life. Postharvest Biol. Technol, 2013; 82: 70-75.

[10] Sohail M, Ayub M, Khalil S A, Zeb A, Ullah F, Afridi S R, et al. Effect of calcium chloride treatment on post-harvest quality of peach fruit during cold storage. Int. Food Res. J., 2015; 22: 2225-2229.

[11] Turmanidze T, Gulua1 L, Jgenti M, Wicker L. Effect of calcium chloride treatments on quality characteristics of blackberry, raspberry and strawberry fruits after cold storage. TUR. J. A. F., 2016; 4(12): 1127-1133.

[12] Asghari M, Aghdam M. Impact of salicylic acid on post-harvest physiology of horticultural crops. Trends in Food Science Tech., 2010; 21: 502-509. doi: 10.1016/j.tifs.2010.07.009.

[13] Srivastava M K, Dwivedi U N. Delayed ripening of banana fruit by salicylic acid. Plant Sci., 2000; 158: 87-96.

[14] Zhang Y, Chen K, Zhang S, Ferguson I. The role of salicylic acid in postharvest ripening of kiwifruit. Postharvest Biol. Technol., 2003; 28(1): 67-74.

[15] Huang R H, Liu J H, Lu Y M, Xia R X. Effect of salicylic acid on the antioxidant system in the pulp of 'Cara cara' navel orange (Citrus sinensis L Osbeck) at different storage temperatures. Postharvest Biol. Technol., 2008; 47(3): 168-175.

[16] Luo Z, Chen C, Xie J. Effect of salicylic acid treatment on alleviating postharvest chilling injury of 'Qingnai' plum fruit. Postharvest Biol. Technol., 2011; 62(3): 115-120.

[17] [17] Association of Official Analytical Chemists - International [AOAC]. Official Methods of Analysis, 18th ed. AOAC, Gaithersburg, MD, USA, 2005.

[18] Maskan M. Kinetics of color change of kiwifruits during hot air and microwave drying. J. Food Eng., 2001; 48: 169-175. doi: 10.1016/S0260-8774(00)00154-0.

[19] Alhamdan A, Hassan B, Alkahtani H, Younis M, Abdelkarim D. Quality changes in fresh date fruits (Barhi) during individual quick freezing and conventional slow freezing. Pak. J. Agri. Sci., 2016; 53: 917-924.

[20] Lim J. Hedonic scaling: A review of methods and theory. Food Quality and Preference, 2011; 22: 733-747.

[21] Baliga M S, Baliga B R V, Kandathil S M, Bhat H P, Vayalil P K. A review of the chemistry and pharmacology of the date fruits (Phoenix dactylifera L.). Food Res. Int., 2011; 44:1812-1822.

[22] Zheng Y, Zhang Q. Effects of polyamines and salicylic acid postharvest storage of 'Ponkan' mandarin. ActaHortic., 2004; 632: 317-320.

[23] Lester G E, Grusak M A. Postharvest application of calcium and magnesium to honeydew and netted muskmelons: Effects on tissue ion concentrations, quality, and senescence. J. Amer. Soc. Hort. Sci., 1999; 124(5): 545-552.

[24] Hussain P R, Meena R S, Dar M A, Wani A M. Effect of post-harvest calcium chloride dip treatment and gamma irradiation on storage quality and shelf-life extension of Red delicious apple. J. Food Sci. Technol., 2012; 49(4): 415-426.

[25] Gupta N, Jawandha S K, Gill P S. Effect of calcium on cold storage and postharvest storage quality of peach. J. Food. Sci., 2011; 48: 225-229.

[26] Vandana A K, Suresha G J, Swamy G S K. Impact of calcium chloride pre-storage treatment on Jamun (syzygiumcumini skeels) fruits under cold Storage. The Bioscan., 2015; 10(1): 199-202.

[27] Chen F, Liu H, Yang H, Lai S, Cheng X, Xin Y, et al. Quality attributes and cell wall properties of strawberries (Fragariaannanassa Duch.) under calcium chloride treatment. Food Chem., 2011; 126: 450-459.

[28] Shirzadeh E, Rabiei V, Sharafi Y. Effect of calcium chloride $\left(\mathrm{CaCl}_{2}\right)$ on postharvest quality of apple fruits. African J. Agri. Res., 2011; 6(22): 5139-5143.

[29] Vandana A K, Suresha G J, Hanamant R H. Exogenous application of calcium chloride influences the physico-chemical changes in sugar apples (Annona squamosa L.) fruits in cold storage. Int. J. Adv. Res., 2016; 4(11): 1499-1505.

[30] Conway J M. Distinguishing contextual performance from task performance for managerial jobs. Journal of Applied Psychology, 1999; 84: 3-13.

[31] White P, Broadley M. Calcium in plants. Annals of Botany, 2003; 92: 487-511. 